\title{
An Outline for a Theory of the Emotions
}

\section{Michalis}

\section{King's College, London, U.K.}

\section{The Phenomenolgy of Emotion}

Emotion is "a way of acting" [3]. Acting that is directed toward the self when action in the external world is of no avail, but which in any case is "intended as a transformation of the world, not of the self" [3]. In that lies the deception of emotion, its magical quality as well.

Emotion, in the context of Sartre's theory of the emotions arises in a world charged with negative affect and seeks to avert, mask or elude the lack of instrumental means for reaching to an end. It does so by switching action on to another plane, that which in the theory is referred to as the "non-instrumental (magical) field of unreality". [3]

The contrast between our perception of the world as it has been experienced in the past and its present form apart from bringing about, or forcing a new awareness of the self in a changed environment, it becomes a source of tension. This tension comes to signify the organism's need, need more than desire, for a way to adapt to, and master the conditions of a new environment. It may be positive or negative depending on the nature of the conditions, or changes the organism is trying to adapt, its strength varying according to, and being a measure of the organism's perceived ability or the perceived difficulty of adapting to the new conditions.

Emotional behaviour arises in reaction to a rising tension as all action to an end is inhibited by internal or external constraints. It (emotion) acts to resolve the tension by resorting on to another form of behaviour, and in a way that masks, or eludes any sense of inferiority. By so transforming (our consciousness of) the world, each of the emotions constitutes a "distinct mechanism of self deception". [3]

\section{The Neurobiological Correlates of Emotional Bchaviour.}

There is evidence - anatomic (electro) physiological, and pharmacological for the localization of tension in the cingulate gyrus [2]. Afferents from the cingulate gyrus project both to the amygdala and the hippocampus. Feedback signals from the hippocampus act to control the activity in the cingulate cortex in relation to the outcome of the comparison (in the subiculum) between actual and expected events.

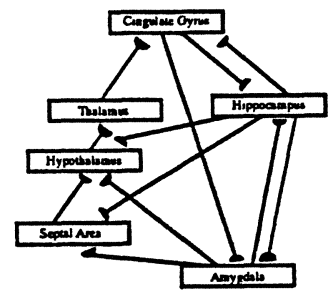

Increased activity in the cingulate gyrus, in response to the breakdown of adaptation - coded in the hippocampus by the mismatch between the actual and expected outcome of an action, facilitates activation of the amygdala by the cortex. Cortical inputs to the amygdala come from the sensory representation of external stimuli associated with the breakdown of behaviour. Amygdalo-hippocampal interactions, superimposed over intrinsic connections in the amygdala then act not only to select an appropriate emotional reaction, but also to calibrate weighted signals from the cortex to the amygdala so that these signals could, at a later stage elicit the same (emotional) response without mediation from the hippocampus.

\section{References}

1. J.A. Gray, (1982) The Neuro-psychology of Anxiety, Oxford, Clarendon Press.

2. B. Kissin, (1992), Conscious and Unconscious Programs in the Brain, Plenum Press.

3. J.P. Sartre (1962), Sketch for a Theory of the Emotions, Methuen \& Co Ltd.

4. J.G. Taylor and M. Reiss (1992), Docs the Hippocampus Store Temporal Patterns Neural Network World 3-4/92, pp 365-384. 